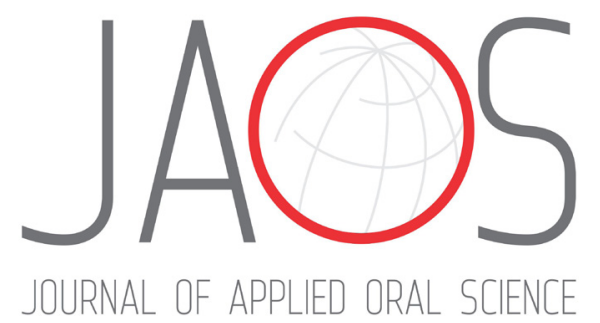

Talita Mendes da Silva VENTURA ${ }^{1}$

Nathalia Regina RIBEIRO ${ }^{1}$

Aline Salgado DIONIZIO ${ }^{1}$

Isabela Tomazini SABINO ${ }^{1}$

Marília Afonso Rabelo BUZALAF ${ }^{1}$

\section{Standardization of a protocol for shotgun proteomic analysis of saliva}

\section{Abstract}

Saliva contains numerous proteins and peptides, each of them carries a number of biological functions that are very important in maintaining the oral cavity health and also yields information about both local and systemic diseases. Currently, proteomic analysis is the basis for large-scale identification of these proteins and discovery of new biomarkers for distinct diseases. Objective: This study compared methodologies to extract salivary proteins for proteomic analysis. Material and Methods: Saliva samples were collected from 10 healthy volunteers. In the first test, the necessity for using an albumin and IgG depletion column was evaluated, employing pooled samples from the 10 volunteers. In the second test, the analysis of the pooled samples was compared with individual analysis of one sample. Salivary proteins were extracted and processed for analysis by LC-ESI-MS/ MS. Results: In the first test, we identified only 35 proteins using the albumin and IgG depletion column, while we identified 248 proteins without using the column. In the second test, the pooled sample identified 212 proteins, such as carbonic anhydrase 6, cystatin isoforms, histatins 1 and 3, lysozyme C, mucin 7, protein S100A8 and S100A9, and statherin, while individual analysis identified 239 proteins, among which are carbonic anhydrase 6, cystatin isoforms, histatin 1 and 3, lactotransferrin, lyzozyme C, mucin 7, protein S100A8 and S100A9, serotransferrin, and statherin. Conclusions: The standardization of protocol for salivary proteomic analysis was satisfactory, since the identification detected typical salivary proteins, among others. The results indicate that using the column for depletion of albumin and IgG is not necessary and that performing individual analysis of saliva samples is possible.

'Universidade de São Paulo, Faculdade de Odontologia de Bauru, Departamento de Ciências Biológicas, Bauru, São Paulo, Brasil.
Keywords: Methods. Proteomics. Standardization. Saliva. 


\section{Introduction}

Saliva is a biological fluid composed of more than $99 \%$ water and less than $1 \%$ protein, electrolytes and other low-molecular-weight components. It originates mainly from three pairs of major salivary glands (parotid, submandibular and sublingual glands), as well as from 300 to 400 minor salivary glands present in the oral cavity. Saliva plays a key role in lubrication, chewing, swallowing and digestion. It protects the oral tissues and also provides biomarkers for local and systemic diseases ${ }^{17}$. Therefore, saliva contains more than 2000 proteins and peptides that are involved in an infinity of different biological functions in the oral cavity ${ }^{17}$. Saliva still plays a large role in the formation of acquired pellicle, which begins only a few seconds after exposure of the enamel to saliva ${ }^{5}$.

Human saliva is a biological fluid with enormous diagnostic potential. Because saliva can be noninvasively collected, it provides an attractive alternative for blood, serum or plasma ${ }^{13}$

In the human saliva were identified 1166 proteins, and high portions of these proteins were found in serum. Currently, progress in salivary diagnostics has demonstrated that these contents can be very informative for detection of oral and systematic diseases ${ }^{20}$.

Proteomics, a new field of research centered on identification, quantitation, and characterization of proteins and their interplay, is largely based on the robustness, sensitivity, speed, and throughput of mass spectrometric procedures ${ }^{6}$. Currently, mass spectrometry is the basic technology for large-scale identification of these salivary proteins, and proteomic analysis of saliva has distinct advantages over blood, especially for proteins of low abundance ${ }^{17,18}$. One of the main challenges in proteomic analysis is the fact that highly abundant proteins can impair the identification of low-abundance proteins, considering the equipment dynamic range. In the case of saliva, albumin and immunoglobulin $\mathrm{G}$ ( $\mathrm{IgG}$ ), they are very abundant, and some authors have recommended using columns for depletion of these proteins during the extraction procedure ${ }^{7,8}$. Saliva functions are not only restricted to process food for digestion, considering that it contains a large number of proteins, which play important roles in the regulation of the immune defense and endocrine system and in the maintenance of mucosal tissue and dental health ${ }^{1}$.
Saliva may contain locally expressed proteins and other substances called biomarkers, which can be used as diseases' indicators, be closely related to an individual's health condition and change greatly when diseases occur. In general, most studies view saliva wrongly as a homogeneous body fluid. It is also not stable, but constantly in change, and its composition is affected among other things by sampling methodology, environment, periodicity, oral hygiene, psychological status and general health $6,13,20$.

Considering the importance of saliva in the oral cavity homeostasis, as well as its great potential as a diagnostic fluid, the aim of this study was to standardize a protocol to extract salivary proteins for further proteomic analysis. In the first test, we evaluated the need for using an albumin and IgG column to deplete these proteins during protein extraction. In the second test, we compared analysis of samples pooled from 10 volunteers with samples from individual analysis.

\section{Material and methods}

\section{Ethical aspects and human subjects}

The protocol of this study was submitted and approved by the Ethics Committee in Research with Human Beings of the Bauru School of Dentistry FOB/USP (CAAE No. 61484116.0.0000.5417). Ten participants with good general and oral health took part of this study, which was based on previous in vivo studies ${ }^{18}$. Inclusion criteria were: nonsmokers with good general and oral health, stimulated salivary flow $>1 \mathrm{~mL} / \mathrm{min}$ and unstimulated salivary flow $>0.25$ $\mathrm{mL} / \mathrm{min}$, salivary $\mathrm{pH}>6.0$.

\section{Saliva collection}

The volunteers were asked to rest for $15 \mathrm{~min}$ before collecting saliva, sitting upright. They were asked not to speak or eat before beginning to collect saliva. First, they rinsed their mouths with $5 \mathrm{~mL}$ of drinking deionized water, then they were asked to swallow saliva for $5 \mathrm{~min}$. After this period, the volunteers spit out all the saliva accumulated in the mouth in a plastic tube immersed in ice for 10 min (unstimulated flow). The saliva samples were immediately centrifuged at $14,000 \mathrm{~g}$ for $15 \mathrm{~min}$ at $4^{\circ} \mathrm{C}$ to remove all debris, such as insoluble material, cell debris and food debris. The supernatant from each sample was collected and 
frozen at $-80^{\circ} \mathrm{C}$ until analysis. These procedures were based on previous studies ${ }^{6,18}$.

\section{Preparation of the saliva samples}

The experiments were performed into two phases. The first test was done to evaluate whether or not the albumin \& IgG Depletion SpinTrap column (GE Healthcare ${ }^{\circledR}$, Buckinghamshire, UK) should be used. The second test was performed after the results of the first to compare analysis of salivary samples pooled from all the 10 volunteers with analysis of an individual sample from one selected volunteer.

For the first test, $100 \mu$ l of saliva from each volunteer was taken and transferred to 10 new tubes. For the second test, $100 \mu \mathrm{l}$ of each saliva sample was also taken and transferred to 10 new tubes to constitute the pool, while $1 \mathrm{ml}$ of saliva was taken from only one of the volunteers (randomly selected) for individual analysis.

Proteins from the saliva samples were extracted using an equal volume of a solution containing 6 $M$ urea, 2 thiourea in $50 \mathrm{mM} \mathrm{NH}_{4} \mathrm{HCO}_{3} \mathrm{pH}$ 7.8. The samples were vortexed at $4^{\circ} \mathrm{C}$ for $10 \mathrm{~min}$, sonicated for $5 \mathrm{~min}$ and centrifuged at $14,000 \mathrm{~g}$ at $4^{\circ} \mathrm{C}$ for 10 min. This step was repeated once more. For the first test (with or without the use of the albumin and IgG depletion column), we added $100 \mu$ of the extraction solution to each Eppendorf tube. For the second test (pool X individual analysis), we added $100 \mu \mathrm{l}$ of the extraction solution in each Eppendorf tube (for the samples that will be pooled later on), while for the individual sample, we added $1 \mathrm{ml}$ of the extraction solution. In all the cases, an equal volume of saliva sample and extraction solution was used. For the pooled samples, we placed the content of the 10 tubes in one tube after the extraction procedure, constituting the pool for further analysis.

After extraction, for the first test, the pooled sample was loaded into the albumin \& IgG depletion columns, according to the manufacturer's instructions Albumin \& IgG Depletion SpinTrap column (GE Healthcare ${ }^{\circledR}$, Buckinghamshire, UK). We did not use this column in the second test.

The samples were then concentrated to $150 \mu \mathrm{l}$ in Falcon Amicon tubes (Merck Millipore ${ }^{\circledR}$, Tullagreen, County Cork, Ireland). After concentration, the samples were reduced with $5 \mathrm{mM}$ dithiothreitol (DTT) for $40 \mathrm{~min}$ at $37^{\circ} \mathrm{C}$, alkylated with $10 \mathrm{mM}$ iodoacetamide (IAA) for $30 \mathrm{~min}$ in the dark. After this procedure, we added 100 $\mu \mathrm{l}$ of $50 \mathrm{mM} \mathrm{NH}_{4} \mathrm{HCO}_{3}$, and the samples were digested with $2 \%(\mathrm{w} / \mathrm{w})$ trypsin (Promega ${ }^{\circledR}$, Madison, USA) for 14 hours at $37^{\circ} \mathrm{C}$. After this period, we added $10 \mu$ of $5 \%$ formic acid to stop the trypsin reaction, then the samples were purified and desalted using the C18 Spin columns (Thermo Scientific ${ }^{\circledR}$, Rockford, Illinois, USA) and we withdrew a 1 ul aliquot of each sample from the tests for protein quantification by the Bradford method (Bio-Rad ${ }^{\circledR}$, Hercules, Califórnia, USA) ${ }^{16}$. We resuspended the samples in the solution containing 3\% acetonitrile and $0.1 \%$ formic acid to be submitted to Nano Liquid Chromatography Electron Spray Ionization Tandem Mass Spectrometry - LC-ESI-MS/MS (Waters, Manchester, New Hampshire, UK).

\section{Shotgun label-free quantitative proteomic analysis}

Peptides identification was performed on a nanoACQUITY UPLC-Xevo QTof MS system (Waters, Manchester, New Hampshire, UK). The nanoACQUITY UPLC was equipped with nanoACQUITY HSS T3, analytical reverse phase column (75 $\mu \mathrm{m} \times 150$ $\mathrm{mm}, 1.8 \mu \mathrm{m}$ particle size (Waters, Manchester, New Hampshire, UK). The column was equilibrated with mobile phase A $(0.1 \%$ formic acid in water). Then, the peptides were separated with a linear gradient of $7-85 \%$ mobile phase $B(0.1 \%$ formic acid in ACN) for $70 \mathrm{~min}$ at a flow rate of $0.35 \mu \mathrm{L} / \mathrm{min}$. The column temperature was maintained at $55^{\circ} \mathrm{C}$. The Xevo G2 Q-TOF mass spectrometer was operated in positive nano-electrospray ion mode, and data were collected using the MSE method in elevated energy (19-45 V), which allows data acquisition of both precursor and fragment ions, in one injection. Source conditions used included capillary voltage, $2.5 \mathrm{kV}$; sample cone, $30 \mathrm{~V}$; extraction cone, $5.0 \mathrm{~V}$ and source temperature, $80^{\circ} \mathrm{C}$. Data acquisition occurred over $70 \mathrm{~min}$, and the scan range was 50-2000 Da. The lockspray, used to ensure accuracy and reproducibility, was run with a [Glu1] fibrinopeptide solution (1 pmol/ $\mu \mathrm{L}$ ) at a flow rate of $1 \mu \mathrm{L} / \mathrm{min}$, as a reference ion in positive mode at $\mathrm{m} / \mathrm{z}$ 785.8427. ProteinLynx Global Server (PLGS) version 3.0 was used to process and search the LC-MSE continuum data. Proteins were identified with the embedded ion accounting algorithm in the software and a search of the Homo sapiens database (reviewed only, UniProtKB/Swiss-Prot) downloaded on September 2015 from UniProtKB (http://www. uniprot.org/). The use of human database excludes the identification of bacterial proteins that could be 
present in the saliva.

\section{Results}

In the first test, when the albumin and IgG depletion column was used, the total amount of protein recovered from the pooled samples after extraction was $8 \mu \mathrm{g}$, while only 35 salivary proteins were identified. Among them are proteins typically found in saliva, such as alpha-amylase 1 and 2B, cystatin isoforms, hemoglobin isoforms and mucin 7, among others (Table 1 ). When the depletion column was not used, the amount of protein recovered was much higher $(48.0 \mu \mathrm{g})$ and 248 proteins were identified, among them many typical components of saliva such as alpha-amylase 1 and $2 \mathrm{~B}$, many cystatin isoforms, carbonic anhydrase 6, lactotransferrin, lysozyme C, mucin 7, proline-rich protein 4, protein S100A9, serotransferrin, statherin, several hemoglobin isoforms, among others (Table 2).

In the second test, for comparison of analysis of pooled versus individual sample, the depletion column

Table 1- Salivary proteins identified when the albumin and IgG depletion column was used

\begin{tabular}{|c|c|c|c|}
\hline Accession number & Protein name & score & Cover (\%) \\
\hline P04745 & Alpha-amylase 1 & 7589.70 & 54.99 \\
\hline P19961 & Alpha-amylase 2B & 6833.20 & 47.75 \\
\hline P04280 & Basic salivary proline-rich protein 1 & 488.14 & 43.88 \\
\hline P02812 & Basic salivary proline-rich protein 2 & 3642.44 & 45.67 \\
\hline P49407 & Beta-arrestin-1 & 158.66 & 9.09 \\
\hline P01036 & Cystatin-S & 1465.11 & 31.91 \\
\hline P09228 & Cystatin-AS & 516.59 & 24.11 \\
\hline P01037 & Cystatin-SN & 1378.19 & 21.28 \\
\hline Q9UGM3 & Deleted in malignant brain tumors 1 protein & 98.93 & 2.11 \\
\hline P14867 & Gamma-aminobutyric acid receptor subunit alpha-1 & 92.53 & 7.46 \\
\hline G3V1N2 & HCG1745306_isoform CRA_a & 456.20 & 22.73 \\
\hline P69905 & Hemoglobin subunit alpha & 1306.87 & 28.17 \\
\hline P68871 & Hemoglobin subunit beta & 1659.66 & 66.67 \\
\hline P02042 & Hemoglobin subunit delta & 497.84 & 25.17 \\
\hline A0A0G2JMB2 & Ig alpha-2 chain $\mathrm{C}$ region (Fragment) & 559.94 & 16.76 \\
\hline P01876 & Immunoglobulin heavy constant alpha 1 & 912.82 & 30.59 \\
\hline P01877 & Immunoglobulin heavy constant alpha 2 & 345.30 & 20.00 \\
\hline P01591 & Immunoglobulin J chain & 1363.63 & 36.48 \\
\hline P01834 & Immunoglobulin kappa constant & 333.71 & 51.40 \\
\hline P0CG04 & Immunoglobulin lambda constant 1 & 136.40 & 14.15 \\
\hline PODOY2 & Immunoglobulin lambda constant 2 & 165.46 & 23.58 \\
\hline PODOY3 & Immunoglobulin lambda constant 3 & 153.74 & 23.58 \\
\hline P0CF74 & Immunoglobulin lambda constant 6 & 136.40 & 14.15 \\
\hline B9A064 & Immunoglobulin lambda-like polypeptide 5 & 136.40 & 7.01 \\
\hline P31025 & Lipocalin-1 & 1181.01 & 26.70 \\
\hline Q8TAX7 & Mucin-7 & 95.21 & 3.71 \\
\hline P04746 & Pancreatic alpha-amylase & 6723.99 & 41.49 \\
\hline P01833 & Polymeric immunoglobulin receptor & 305.15 & 15.58 \\
\hline P12273 & Prolactin-inducible protein & 1027.80 & 40.41 \\
\hline АОАОАОМТЗ1 & Proline-rich protein 4 & 8108.76 & 72.29 \\
\hline Q5VSP4 & Putative lipocalin 1-like protein 1 & 958.48 & 6.79 \\
\hline $\mathrm{P} 02810$ & Salivary acidic proline-rich phosphoprotein $1 / 2$ & 8108.76 & 72.29 \\
\hline P02814 & Submaxillary gland androgen-regulated protein 3B & 2090.48 & 65.82 \\
\hline A0A087WZY1 & Uncharacterized protein & 7158.08 & 16.60 \\
\hline Q96DA0 & Zymogen granule protein 16 homolog $B$ & 721.70 & 41.83 \\
\hline
\end{tabular}


Table 2- Salivary proteins identified when the albumin and IgG depletion column was not used

\begin{tabular}{|c|c|c|c|}
\hline Accession number & Protein name & score & Cover $(\%)$ \\
\hline Q15118 & [Pyruvate dehydrogenase (acetyl-transferring)] kinase isozyme 1_mitochondrial & 89.50 & 8.26 \\
\hline P31946 & 14-3-3 protein beta/alpha & 166.37 & 3.25 \\
\hline P62258 & 14-3-3 protein epsilon & 177.85 & 3.14 \\
\hline Q04917 & $14-3-3$ protein eta & 166.37 & 3.25 \\
\hline P61981 & $14-3-3$ protein gamma & 166.37 & 3.24 \\
\hline P31947 & 14-3-3 protein sigma & 166.37 & 3.23 \\
\hline P27348 & $14-3-3$ protein theta & 195.23 & 12.65 \\
\hline P63104 & 14-3-3 protein zeta/delta & 166.37 & 3.27 \\
\hline Q6ZVK8 & 8-oxo-dGDP phosphatase NUDT18 & 138.11 & 19.50 \\
\hline E5KP25 & A/G-specific adenine DNA glycosylase & 242.24 & 5.28 \\
\hline P68032 & Actin_alpha cardiac muscle 1 & 10751.18 & 40.05 \\
\hline P68133 & Actin_alpha skeletal muscle & 10681.87 & 33.95 \\
\hline P62736 & Actin_aortic smooth muscle & 10396.48 & 37.14 \\
\hline P60709 & Actin_cytoplasmic 1 & 18715.02 & 66.67 \\
\hline P63261 & Actin_cytoplasmic 2 & 18715.02 & 66.67 \\
\hline P63267 & Actin_gamma-enteric smooth muscle & 10327.17 & 31.12 \\
\hline Q6P461 & Acyl-coenzyme A synthetase ACSM6_mitochondrial & 399.16 & 13.33 \\
\hline Q9UIF7 & Adenine DNA glycosylase & 242.24 & 5.31 \\
\hline Q9Y6U3 & Adseverin & 51.66 & 5.17 \\
\hline C9JKR2 & Albumin_isoform CRA_k & 25004.47 & 77.94 \\
\hline P02763 & Alpha-1-acid glycoprotein 1 & 259.49 & 7.46 \\
\hline P01009 & Alpha-1-antitrypsin & 114.17 & 14.59 \\
\hline P01023 & Alpha-2-macroglobulin & 195.37 & 14.25 \\
\hline P04745 & Alpha-amylase 1 & 125762.3 & 77.69 \\
\hline P19961 & Alpha-amylase 2B & 85518.55 & 67.91 \\
\hline Q69YU3 & Ankyrin repeat domain-containing protein $34 \mathrm{~A}$ & 213.80 & 23.19 \\
\hline Q5T3N1 & Annexin (Fragment) & 419.03 & 34.31 \\
\hline P04083 & Annexin A1 & 454.28 & 33.53 \\
\hline P03973 & Antileukoproteinase & 822.96 & 40.15 \\
\hline Q16671 & Anti-Muellerian hormone type-2 receptor & 646.30 & 18.32 \\
\hline P02647 & Apolipoprotein A-I & 436.68 & 32.58 \\
\hline B1APP8 & ATP-dependent 6-phosphofructokinase_platelet type & 156.72 & 21.29 \\
\hline 014965 & Aurora kinase $\mathrm{A}$ & 187.17 & 8.93 \\
\hline P04280 & Basic salivary proline-rich protein 1 & 13742.73 & 44.39 \\
\hline P02812 & Basic salivary proline-rich protein 2 & 36329.24 & 69.23 \\
\hline Q6W2J9 & BCL-6 corepressor & 171.50 & 2.34 \\
\hline P61769 & Beta-2-microglobulin & 7681.87 & 54.62 \\
\hline Q562R1 & Beta-actin-like protein 2 & 1631.58 & 17.02 \\
\hline Q96DR5 & BPI fold-containing family A member 2 & 4054.46 & 40.56 \\
\hline Q8TDL5 & BPI fold-containing family B member 1 & 238.42 & 27.27 \\
\hline Q8N4F0 & BPI fold-containing family B member 2 & 4941.71 & 32.97 \\
\hline Q8N4G4 & CA6 protein & 236.85 & 4.47 \\
\hline P23280 & Carbonic anhydrase 6 & 1927.33 & 43.83 \\
\hline P07339 & Cathepsin D & 153.05 & 17.96 \\
\hline HOYDT2 & Cathepsin W (Fragment) & 152.45 & 12.32 \\
\hline A0A087X2B6 & Cell cycle and apoptosis regulator protein 2 & 186.22 & 13.60 \\
\hline O60308 & Centrosomal protein of $104 \mathrm{kDa}$ & 36.50 & 3.35 \\
\hline O94986 & Centrosomal protein of $152 \mathrm{kDa}$ & 24.18 & 5.03 \\
\hline 075153 & Clustered mitochondria protein homolog & 864.26 & 9.93 \\
\hline P35606 & Coatomer subunit beta' & 186.05 & 6.73 \\
\hline G3V1A4 & Cofilin 1 (Non-muscle)_isoform CRA_a & 613.65 & 18.79 \\
\hline P23528 & Cofilin-1 & 613.65 & 16.87 \\
\hline Q8TD31 & Coiled-coil alpha-helical rod protein 1 & 47.65 & 2.43 \\
\hline Q9P0B6 & Coiled-coil domain-containing protein 167 & 170.32 & 15.46 \\
\hline P01024 & Complement C3 & 181.96 & 9.32 \\
\hline Q2VPA4 & Complement component receptor 1 -like protein & 148.59 & 7.21 \\
\hline P04080 & Cystatin-B & 3144.06 & 55.10 \\
\hline P01034 & Cystatin-C & 1547.12 & 31.51 \\
\hline
\end{tabular}

Continued on the next page 
Continued from previous page

\begin{tabular}{|c|c|c|c|}
\hline P28325 & Cystatin-D & 535.37 & 47.89 \\
\hline P01036 & Cystatin-S & 41046.83 & 73.76 \\
\hline P09228 & Cystatin-SA & 21107.61 & 53.90 \\
\hline P01037 & Cystatin-SN & 40764.24 & 68.09 \\
\hline P54108 & Cysteine-rich secretory protein 3 & 371.45 & 26.94 \\
\hline Q9UGM3 & Deleted in malignant brain tumors 1 protein & 274.04 & 6.80 \\
\hline Q8IYB7 & DIS3-like exonuclease 2 & 192.96 & 5.42 \\
\hline Q9NVU0 & DNA-directed RNA polymerase III subunit RPC5 & 187.74 & 4.66 \\
\hline Q1HG43 & Dual oxidase maturation factor 1 & 248.89 & 13.12 \\
\hline O95714 & E3 ubiquitin-protein ligase HERC2 & 190.34 & 5.05 \\
\hline Q8NG27 & E3 ubiquitin-protein ligase Praja-1 & 680.83 & 14.31 \\
\hline P43897 & Elongation factor Ts_mitochondrial & 129.02 & 9.23 \\
\hline QOPNE2 & Elongator complex protein 6 & 63.64 & 13.53 \\
\hline V9HW75 & Epididymis secretory protein Li 109 & 337.33 & 22.86 \\
\hline P02675 & Fibrinogen beta chain & 420.77 & 40.73 \\
\hline P02679 & Fibrinogen gamma chain & 453.82 & 22.52 \\
\hline Q0PRL4 & Forkhead box P2 variant 3 & 142.49 & 10.19 \\
\hline Q8N6B5 & Forkhead box P2_isoform CRA_d (Fragment) & 142.49 & 11.84 \\
\hline O15409 & Forkhead box protein P2 & 199.65 & 12.45 \\
\hline O95872 & G patch domain and ankyrin repeat-containing protein 1 & 268.32 & 17.70 \\
\hline P19526 & Galactoside 2-alpha-L-fucosyltransferase 1 & 174.70 & 13.42 \\
\hline P48058 & Glutamate receptor 4 & 50.22 & 2.55 \\
\hline P04406 & Glyceraldehyde-3-phosphate dehydrogenase & 190.90 & 16.72 \\
\hline P00738 & Haptoglobin & 349.21 & 24.88 \\
\hline G3V1N2 & HCG1745306_isoform CRA_a & 22783.57 & 58.18 \\
\hline P69905 & Hemoglobin subunit alpha & 27452.86 & 59.15 \\
\hline P68871 & Hemoglobin subunit beta & 49667.26 & 95.24 \\
\hline P02042 & Hemoglobin subunit delta & 9498.60 & 33.33 \\
\hline P02100 & Hemoglobin subunit epsilon & 1940.46 & 6.80 \\
\hline P69891 & Hemoglobin subunit gamma-1 & 1940.46 & 6.80 \\
\hline P69892 & Hemoglobin subunit gamma-2 & 1940.46 & 6.80 \\
\hline $\mathrm{P} 02790$ & Hemopexin & 460.96 & 22.51 \\
\hline P15515 & Histatin-1 & 32092.25 & 36.84 \\
\hline P15516 & Histatin-3 & 7558.25 & 13.73 \\
\hline P57058 & Hormonally up-regulated neu tumor-associated kinase & 218.10 & 3.50 \\
\hline Q9BS19 & HPX protein & 352.10 & 21.65 \\
\hline A0A0G2JMB2 & Ig alpha-2 chain $\mathrm{C}$ region (Fragment) & 22147.53 & 68.24 \\
\hline AOAOAOMS07 & Ig gamma-1 chain $\mathrm{C}$ region (Fragment) & 1490.66 & 45.76 \\
\hline A0A087WYJ9 & Ig mu chain $\mathrm{C}$ region & 2129.91 & 40.71 \\
\hline P04220 & Ig mu heavy chain disease protein & 1800.88 & 31.97 \\
\hline P01876 & Immunoglobulin heavy constant alpha 1 & 25196.43 & 61.19 \\
\hline P01877 & Immunoglobulin heavy constant alpha 2 & 18459.82 & 64.12 \\
\hline P01857 & Immunoglobulin heavy constant gamma 1 & 3671.28 & 50.91 \\
\hline P01859 & Immunoglobulin heavy constant gamma 2 & 729.35 & 38.34 \\
\hline P01860 & Immunoglobulin heavy constant gamma 3 & 487.81 & 24.93 \\
\hline P01861 & Immunoglobulin heavy constant gamma 4 & 599.47 & 20.18 \\
\hline P01871 & Immunoglobulin heavy constant mu & 2171.72 & 47.68 \\
\hline A0A075B7F0 & Immunoglobulin heavy variable 3/OR16-10 (non-functional) (Fragment) & 378.41 & 9.48 \\
\hline S4R460 & Immunoglobulin heavy variable 3/OR16-9 (non-functional) & 5403.28 & 31.25 \\
\hline P01762 & Immunoglobulin heavy variable 3-11 & 378.41 & 9.40 \\
\hline P01766 & Immunoglobulin heavy variable 3-13 & 378.41 & 9.48 \\
\hline $\mathrm{AOA0C4DH32}$ & Immunoglobulin heavy variable 3-20 (Fragment) & 378.41 & 9.40 \\
\hline A0A0B4J1V1 & Immunoglobulin heavy variable 3-21 & 378.41 & 9.40 \\
\hline A0A0B4J1X8 & Immunoglobulin heavy variable 3-43 & 378.41 & 9.32 \\
\hline P01763 & Immunoglobulin heavy variable 3-48 & 378.41 & 9.40 \\
\hline P01780 & Immunoglobulin heavy variable 3-7 & 401.30 & 17.09 \\
\hline P01782 & Immunoglobulin heavy variable 3-9 & 378.41 & 9.32 \\
\hline P01591 & Immunoglobulin $\mathrm{J}$ chain & 18415.28 & 42.14 \\
\hline P01834 & Immunoglobulin kappa constant & 16816.83 & 85.98 \\
\hline P0CG04 & Immunoglobulin lambda constant 1 & 9338.45 & 77.36 \\
\hline
\end{tabular}

Continued on the next page 
Continued from previous page

\begin{tabular}{|c|c|c|c|}
\hline PODOY2 & Immunoglobulin lambda constant 2 & 13921.14 & 77.36 \\
\hline PODOY3 & Immunoglobulin lambda constant 3 & 13921.14 & 77.36 \\
\hline P0CF74 & Immunoglobulin lambda constant 6 & 13267.04 & 50.94 \\
\hline A0M8Q6 & Immunoglobulin lambda constant 7 & 10499.89 & 36.79 \\
\hline B9A064 & Immunoglobulin lambda-like polypeptide 5 & 9338.45 & 38.32 \\
\hline P08069 & Insulin-like growth factor 1 receptor & 32.75 & 5.63 \\
\hline P06870 & Kallikrein-1 & 227.71 & 10.31 \\
\hline Q9Y5K2 & Kallikrein-4 & 304.56 & 17.72 \\
\hline P13645 & Keratin_type I cytoskeletal 10 & 297.80 & 2.05 \\
\hline Q99456 & Keratin_type I cytoskeletal 12 & 421.18 & 14.17 \\
\hline P13646 & Keratin_type I cytoskeletal 13 & 4810.33 & 46.94 \\
\hline P02533 & Keratin_type I cytoskeletal 14 & 158.42 & 4.24 \\
\hline P19012 & Keratin_type I cytoskeletal 15 & 1164.86 & 14.25 \\
\hline P08779 & Keratin_type I cytoskeletal 16 & 158.42 & 4.23 \\
\hline Q04695 & Keratin_type I cytoskeletal 17 & 143.47 & 2.08 \\
\hline P08727 & Keratin_type I cytoskeletal 19 & 529.84 & 6.75 \\
\hline P35908 & Keratin_type II cytoskeletal 2 epidermal & 300.25 & 22.07 \\
\hline Q01546 & Keratin_type II cytoskeletal 2 oral & 165.14 & 12.07 \\
\hline P19013 & Keratin_type II cytoskeletal 4 & 876.71 & 42.13 \\
\hline P13647 & Keratin_type II cytoskeletal 5 & 489.99 & 7.97 \\
\hline P02538 & Keratin_type II cytoskeletal $6 \mathrm{~A}$ & 794.78 & 31.56 \\
\hline P04259 & Keratin_type II cytoskeletal 6B & 765.88 & 28.01 \\
\hline P48668 & Keratin_type II cytoskeletal $6 \mathrm{C}$ & 765.88 & 28.01 \\
\hline 095678 & Keratin_type II cytoskeletal 75 & 190.38 & 3.81 \\
\hline Q5XKE5 & Keratin_type II cytoskeletal 79 & 190.38 & 3.93 \\
\hline 014777 & Kinetochore protein NDC80 homolog & 410.89 & 9.03 \\
\hline P22079 & Lactoperoxidase & 1724.32 & 34.13 \\
\hline P02788 & Lactotransferrin & 382.65 & 32.11 \\
\hline Q9C099 & Leucine-rich repeat and coiled-coil domain-containing protein 1 & 270.77 & 9.98 \\
\hline Q9NPC1 & Leukotriene B4 receptor 2 & 209.15 & 4.37 \\
\hline P31025 & Lipocalin-1 & 19334.38 & 57.95 \\
\hline P28330 & Long-chain specific acyl-CoA dehydrogenase_mitochondrial & 137.44 & 9.07 \\
\hline Q8IYD9 & Lung adenoma susceptibility protein 2 & 141.09 & 9.14 \\
\hline P61626 & Lysozyme C & 10190.75 & 70.27 \\
\hline Q14680 & Maternal embryonic leucine zipper kinase & 208.24 & 8.14 \\
\hline P42679 & Megakaryocyte-associated tyrosine-protein kinase & 156.39 & 10.85 \\
\hline P01033 & Metalloproteinase inhibitor 1 & 858.61 & 44.44 \\
\hline Q2QL34 & Mpv17-like protein & 240.73 & 11.73 \\
\hline Q8TAX7 & Mucin-7 & 11686.20 & 15.65 \\
\hline Q8NCY6 & Myb/SANT-like DNA-binding domain-containing protein 4 & 176.81 & 11.30 \\
\hline P24158 & Myeloblastin & 175.85 & 4.69 \\
\hline Q8NCE2 & Myotubularin-related protein 14 & 342.16 & 19.38 \\
\hline Q9NYA4 & Myotubularin-related protein 4 & 234.57 & 15.82 \\
\hline F8WCT3 & NEDD8-conjugating enzyme UBE2F & 167.98 & 37.18 \\
\hline P59665 & Neutrophil defensin 1 & 1037.46 & 17.02 \\
\hline P59666 & Neutrophil defensin 3 & 1037.46 & 17.02 \\
\hline O00221 & NF-kappa-B inhibitor epsilon & 176.16 & 6.80 \\
\hline Q2L696 & Nucb2 splice variant & 337.33 & 24.62 \\
\hline Q14980 & Nuclear mitotic apparatus protein 1 & 278.08 & 4.96 \\
\hline Q9Y618 & Nuclear receptor corepressor 2 & 44.62 & 3.33 \\
\hline A0A087WSV8 & Nucleobindin 2_isoform CRA_b & 337.33 & 22.86 \\
\hline P80303 & Nucleobindin-2 & 337.33 & 22.86 \\
\hline O75414 & Nucleoside diphosphate kinase 6 & 140.72 & 14.52 \\
\hline C9JQB1 & Nucleoside diphosphate kinase & 140.72 & 19.15 \\
\hline Q9GZK3 & Olfactory receptor 2B2 & 166.49 & 19.33 \\
\hline Q5SZR7 & Ornithine decarboxylase antizyme 3 & 300.95 & 18.55 \\
\hline Q7RTY7 & Ovochymase-1 & 190.59 & 10.05 \\
\hline P04746 & Pancreatic alpha-amylase & 79860.79 & 59.10 \\
\hline P13796 & Plastin-2 & 364.90 & 18.02 \\
\hline
\end{tabular}

Continued on the next page 
Continued from previous page

\begin{tabular}{|c|c|c|c|}
\hline P13797 & Plastin-3 & 259.13 & 4.29 \\
\hline P01833 & Polymeric immunoglobulin receptor & 10715.77 & 41.62 \\
\hline Q6S8J3 & POTE ankyrin domain family member $E$ & 7556.27 & 11.07 \\
\hline A5A3E0 & POTE ankyrin domain family member $F$ & 7557.11 & 13.67 \\
\hline P0CG38 & POTE ankyrin domain family member I & 6915.24 & 6.79 \\
\hline P0CG39 & POTE ankyrin domain family member $\mathrm{J}$ & 2868.60 & 5.97 \\
\hline P51531 & Probable global transcription activator SNF2L2 & 158.85 & 2.01 \\
\hline Q53EL6 & Programmed cell death protein 4 & 138.40 & 8.74 \\
\hline $\mathrm{P} 12273$ & Prolactin-inducible protein & 31682.10 & 76.71 \\
\hline Q16378 & Proline-rich protein 4 & 312.60 & 21.64 \\
\hline HOY4B9 & Propionyl-CoA carboxylase alpha chain_ mitochondrial (Fragment) & 231.31 & 20.90 \\
\hline P07602 & Prosaposin & 205.84 & 9.35 \\
\hline D6RDZ2 & Protein FAM193B (Fragment) & 266.86 & 35.56 \\
\hline Q14320 & Protein FAM50A & 176.55 & 10.62 \\
\hline Q5VT40 & Protein FAM78B & 141.80 & 10.73 \\
\hline Q8N7I0 & Protein GVQW1 & 164.91 & 17.95 \\
\hline Q6P5S2 & Protein LEG1 homolog & 1162.24 & 29.09 \\
\hline Q8ND56 & Protein LSM14 homolog A & 270.50 & 9.50 \\
\hline Q8WYL5 & Protein phosphatase Slingshot homolog 1 & 322.72 & 3.91 \\
\hline Q5THK1 & Protein PRR14L & 367.74 & 10.13 \\
\hline P06702 & Protein S100-A9 & 571.65 & 39.47 \\
\hline Q96EA4 & Protein Spindly & 138.75 & 2.64 \\
\hline Q58EX7 & Puratrophin-1 & 166.93 & 2.60 \\
\hline Q9BYX7 & Putative beta-actin-like protein 3 & 1002.92 & 10.67 \\
\hline Q5VSP4 & Putative lipocalin 1-like protein 1 & 3906.17 & 11.11 \\
\hline A8K554 & Putative protein ZNF815 & 163.67 & 26.15 \\
\hline Q96GD0 & Pyridoxal phosphate phosphatase & 92.62 & 11.15 \\
\hline H3BR70 & Pyruvate kinase & 336.60 & 18.03 \\
\hline P14618 & Pyruvate kinase PKM & 336.60 & 12.43 \\
\hline Q15276 & Rab GTPase-binding effector protein 1 & 349.01 & 8.24 \\
\hline H3BPI9 & Receptor protein serine/threonine kinase (Fragment) & 641.71 & 47.67 \\
\hline P02810 & Salivary acidic proline-rich phosphoprotein $1 / 2$ & 40463.03 & 26.51 \\
\hline Q14674 & Separin & 32.80 & 4.39 \\
\hline Q9BZL6 & Serine/threonine-protein kinase D2 & 165.21 & 3.87 \\
\hline B4DTS2 & Serine/threonine-protein kinase & 165.21 & 3.83 \\
\hline J3QLP4 & Serine/threonine-protein kinase RIO3 (Fragment) & 335.03 & 50.56 \\
\hline G3V5U8 & Serine/threonine-protein phosphatase $2 \mathrm{~A}$ regulatory subunit B" subunit gamma & 157.81 & 24.53 \\
\hline P02787 & Serotransferrin & 5631.55 & 44.41 \\
\hline P02768 & Serum albumin & 65771.62 & 81.28 \\
\hline P40763 & Signal transducer and activator of transcription 3 & 43.20 & 6.10 \\
\hline Q9UBC9 & Small proline-rich protein 3 & 424.01 & 65.09 \\
\hline $\mathrm{A} 1 \mathrm{~L} 4 \mathrm{H} 1$ & Soluble scavenger receptor cysteine-rich domain-containing protein SSC5D & 62.36 & 2.67 \\
\hline P02808 & Statherin & 52769.28 & 53.23 \\
\hline P02814 & Submaxillary gland androgen-regulated protein $3 \mathrm{~B}$ & 52053.05 & 65.82 \\
\hline Q9UMS6 & Synaptopodin-2 & 184.00 & 1.83 \\
\hline G5E9B5 & TCF3 (E2A) fusion partner (In childhood Leukemia)_isoform CRA_b & 165.61 & 19.67 \\
\hline Q8WW35 & Tctex 1 domain-containing protein 2 & 188.69 & 14.08 \\
\hline Q7Z6L1 & Tectonin beta-propeller repeat-containing protein 1 & 350.11 & 12.62 \\
\hline Q9UKR8 & Tetraspanin-16 & 313.97 & 27.35 \\
\hline P20061 & Transcobalamin-1 & 230.38 & 20.32 \\
\hline A6H8Y1 & Transcription factor TFIIIB component B" homolog & 167.29 & 2.82 \\
\hline 095359 & Transforming acidic coiled-coil-containing protein 2 & 372.27 & 6.41 \\
\hline P55072 & Transitional endoplasmic reticulum ATPase & 236.03 & 10.92 \\
\hline P29401 & Transketolase & 133.40 & 13.80 \\
\hline Q8NDV7 & Trinucleotide repeat-containing gene $6 \mathrm{~A}$ protein & 180.44 & 3.98 \\
\hline K7EQY5 & Tyrosine-protein kinase & 156.39 & 10.87 \\
\hline Q86TW2 & Uncharacterized aarF domain-containing protein kinase 1 & 174.76 & 10.57 \\
\hline H3BMD7 & Uncharacterized protein (Fragment) & 240.73 & 19.49 \\
\hline A0A087WZK3 & Uncharacterized protein (Fragment) & 469.24 & 43.09 \\
\hline
\end{tabular}

Continued on the next page 
Continued from previous page

\begin{tabular}{|c|c|c|c|}
\hline A0A087WZY1 & Uncharacterized protein & 40463.03 & 16.60 \\
\hline A0A087WUV0 & Uncharacterized protein & 464.85 & 8.62 \\
\hline E7ESA3 & Uncharacterized protein & 188.69 & 18.87 \\
\hline Q9HB07 & UPF0160 protein MYG1_mitochondrial & 435.46 & 12.23 \\
\hline Q9NY84 & Vascular non-inflammatory molecule 3 & 540.71 & 10.58 \\
\hline Q14508 & WAP four-disulfide core domain protein 2 & 1637.99 & 33.87 \\
\hline E9PDB0 & WD repeat-containing protein 49 & 424.40 & 5.02 \\
\hline Q86UP3 & Zinc finger homeobox protein 4 & 205.12 & 3.06 \\
\hline Q5FWF6 & Zinc finger protein 789 & 138.52 & 9.41 \\
\hline Q17R98 & Zinc finger protein 827 & 296.41 & 2.87 \\
\hline P25311 & Zinc-alpha-2-glycoprotein & 5026.17 & 55.03 \\
\hline Q96DA0 & Zymogen granule protein 16 homolog B & 47333.93 & 56.73 \\
\hline
\end{tabular}

was not used. For the pooled sample, the amount of protein recovered after extraction was $54.02 \mu \mathrm{g}$, which allowed the identification of 212 proteins, including alpha-amylase 1 and 2B, carbonic anhydrase 6, cystatin isoforms ( $B, C, D, S, S A, S N)$, histatin 1 and 3, lysozyme $C$, mucin 7, protein S100A8 and S100A9, statherin, several hemoglobin isoforms, among others (Table 3). In the analysis of the individual sample, $25.13 \mu \mathrm{g}$ of total protein were obtained and 239 proteins were identified, among which are alphaamylase 1 and 2B, alpha-enolase, carbonic anhydrase 6 , many cystatin isoforms ( $B, C-D, S, S A, S N)$, histatin 1 and 3 , Ig alpha-2 chain $C$ region, Ig a chain $C$ region, lactotransferrin, lysozyme C, mucin 7, protein S1008 and S100A9, serotransferrin, statherin, among other proteins (Table 4).

\section{Discussion}

This study aimed at standardizing a protocol for proteomic analysis of saliva that is sensitive, easy to perform and of low cost, to be used in future experiments involving quantitative shotgun proteomics. The first issue to be solved was related to the necessity of depletion of highly abundant proteins in saliva, such as albumin and $\mathrm{IgG}^{8,14}$ that could mask and make difficult the identification of low abundance biomarkers. Krief and collaborators ${ }^{7}$ (2011) evaluated whether depletion of salivary amylase, albumin and IgGs could improve the ability to visualize proteins in two-dimensional gel electrophoresis (2-DE) in oral fluids. They observed 36 new spots after depletion, and 58 spots showed more than twofold increase intensity after depletion?. Therefore, we hypothesized that this better identification profile could occur not only in two-dimensional gel electrophoresis (2-DE), but also in shotgun proteomics, when albumin and IgG were depleted. Thus, in the first test, we compared the use or not of the albumin and IgG depletion column after the extraction process of the salivary proteins. For this, we used a pool of ten saliva samples. When the column was used, only 35 proteins were identified (Table 1). This figure increased to 248 when the column was not used (Table 2 ). We believe this occurred because, when using the albumin and IgG depletion column, there was also depletion of other proteins, since using the column increases one more process in the methodology. We also believe that many proteins could bind to albumin and IgGs, thus being depleted together. Among the identified proteins, in both situations, are those typically found in saliva. By contrast, when the depletion column was used, classical salivary proteins such as 14-3-3 proteins, histatins, statherin, lactoperoxidase, lactotransferrin, lysozyme C, neutrophil defensins, protein S100A9, serotransferrin and some cystatin isoforms were not identified. Thus, contrary to what was observed in gel-based proteomics ${ }^{7}$, in shotgun proteomics the use of albumin and IgG depletion column impaired protein identification according to our workflow. Some studies, in spite of that, report advantages in using depletion columns when more than one workflow is employed ${ }^{14}$. However, this increases the time and cost of the analysis.

In the second test, we compared analysis of pooled samples (from ten individuals) versus individual analysis, without using the depletion column. In the individual analysis 239 proteins were identified (Table 4), while 212 proteins were identified in the pooled sample (Table 3). One-hundred and twenty three proteins were common to both groups (data not shown), and among them are most of the proteins typically found in saliva. The proteins exclusively found in the individual sample or in the pooled sample are not typically reported in saliva, which might be related to 
Table 3- Proteins of the saliva identified in the pool analysis

\begin{tabular}{|c|c|c|c|}
\hline Accession number & Protein name & score & Cover(\%) \\
\hline P16885 & 1-phosphatidylinositol 4_5-bisphosphate phosphodiesterase gamma-2 & 314.78 & 4.51 \\
\hline P68032 & Actin_alpha cardiac muscle 1 & 6085.31 & 31.30 \\
\hline P68133 & Actin_alpha skeletal muscle & 6085.31 & 31.30 \\
\hline P62736 & Actin_aortic smooth muscle & 4676.94 & 28.38 \\
\hline P60709 & Actin_cytoplasmic 1 & 17496 & 67.20 \\
\hline P63261 & Actin_cytoplasmic 2 & 17496 & 67.20 \\
\hline P63267 & Actin_gamma-enteric smooth muscle & 4676.94 & 28.46 \\
\hline Q01518 & Adenylyl cyclase-associated protein 1 & 440.27 & 26.11 \\
\hline C9JKR2 & Albumin_isoform CRA_k & 26466.72 & 74.82 \\
\hline P01009 & Alpha-1-antitrypsin & 2252.60 & 22.97 \\
\hline P01023 & Alpha-2-macroglobulin & 665.70 & 22.86 \\
\hline P04745 & Alpha-amylase 1 & 153591.90 & 78.86 \\
\hline P19961 & Alpha-amylase 2B & 110753.50 & 58.51 \\
\hline P06733 & Alpha-enolase & 1637.76 & 33.87 \\
\hline Q01484 & Ankyrin-2 & 52.62 & 2.75 \\
\hline P03973 & Antileukoproteinase & 701.53 & 28.03 \\
\hline P63010 & AP-2 complex subunit beta & 338.39 & 2.35 \\
\hline P02647 & Apolipoprotein A-I & 612.31 & 39.70 \\
\hline P02652 & Apolipoprotein A-II & 886.78 & 69.00 \\
\hline Q5FYB0 & Arylsulfatase J & 389.18 & 10.35 \\
\hline Q8IYB8 & ATP-dependent RNA helicase SUPV3L1_ mitochondrial & 235.17 & 6.23 \\
\hline P04280 & Basic salivary proline-rich protein 1 & 3925.20 & 58.67 \\
\hline P02812 & Basic salivary proline-rich protein 2 & 73554.97 & 69.47 \\
\hline P61769 & Beta-2-microglobulin & 3725.17 & 48.74 \\
\hline Q562R1 & Beta-actin-like protein 2 & 1532.83 & 13.30 \\
\hline P13929 & Beta-enolase & 264.78 & 13.36 \\
\hline Q96DR5 & BPI fold-containing family A member 2 & 4561.18 & 58.23 \\
\hline Q8N4F0 & BPI fold-containing family B member 2 & 6508.75 & 30.79 \\
\hline A0A087WXK1 & BRCA1-A complex subunit Abraxas (Fragment) & 332.77 & 16.93 \\
\hline Q8N4G4 & CA6 protein & 419.28 & 4.47 \\
\hline O75638 & Cancer/testis antigen 2 & 716.39 & 19.05 \\
\hline P23280 & Carbonic anhydrase 6 & 15792.21 & 62.01 \\
\hline P00450 & Ceruloplasmin & 71.04 & 8.45 \\
\hline E9PM92 & Chromosome 11 open reading frame 58 & 258.69 & 15.29 \\
\hline P01024 & Complement C3 & 833.42 & 21.17 \\
\hline P51160 & Cone cGMP-specific 3'_5'-cyclic phosphodiesterase subunit alpha' & 232.14 & 11.07 \\
\hline H3BRY3 & Coronin & 502.10 & 22.11 \\
\hline P31146 & Coronin-1A & 502.10 & 24.95 \\
\hline Q92772 & Cyclin-dependent kinase-like 2 & 457.97 & 11.97 \\
\hline P04080 & Cystatin-B & 2288.27 & 45.92 \\
\hline P01034 & Cystatin-C & 3131.85 & 51.37 \\
\hline P28325 & Cystatin-D & 3348.32 & 61.97 \\
\hline P01036 & Cystatin-S & 34860.66 & 73.76 \\
\hline P09228 & Cystatin-SA & 24277.69 & 67.38 \\
\hline P01037 & Cystatin-SN & 23133.23 & 70.21 \\
\hline P54108 & Cysteine-rich secretory protein 3 & 284.38 & 21.63 \\
\hline P32320 & Cytidine deaminase & 1245.08 & 66.44 \\
\hline Q9UGM3 & Deleted in malignant brain tumors 1 protein & 306.82 & 4.97 \\
\hline Q13609 & Deoxyribonuclease gamma & 411.37 & 15.74 \\
\hline А०А0A0MT68 & Deoxyribonuclease & 411.37 & 16.67 \\
\hline P27487 & Dipeptidyl peptidase 4 & 73.31 & 4.83 \\
\hline O60216 & Double-strand-break repair protein rad21 homolog & 322.95 & 19.02 \\
\hline R4GN68 & Dual-specificity mitogen-activated protein kinase kinase 4 & 780.16 & 97.56 \\
\hline V9HW75 & Epididymis secretory protein Li 109 & 954.67 & 25.48 \\
\hline B1AK53 & Espin & 277.28 & 4.80 \\
\hline Q01469 & Fatty acid-binding protein_epidermal & 475.76 & 30.37 \\
\hline Q8NCQ5 & F-box only protein 15 & 465.73 & 3.73 \\
\hline P02679 & Fibrinogen gamma chain & 372.17 & 21.63 \\
\hline
\end{tabular}

Continued on the next page 
Continued from previous page

\begin{tabular}{|c|c|c|c|}
\hline Q08380 & Galectin-3-binding protein & 237.96 & 18.97 \\
\hline P06744 & Glucose-6-phosphate isomerase & 222.14 & 22.04 \\
\hline E7ETY7 & Glutathione peroxidase & 341.42 & 22.78 \\
\hline P09211 & Glutathione S-transferase P & 519.29 & 25.71 \\
\hline P04406 & Glyceraldehyde-3-phosphate dehydrogenase & 407.39 & 11.64 \\
\hline Q8IWJ2 & GRIP and coiled-coil domain-containing protein 2 & 718.24 & 4.81 \\
\hline P00738 & Haptoglobin & 960.32 & 41.87 \\
\hline G3V1N2 & HCG1745306_isoform CRA_a & 11936.33 & 57.27 \\
\hline P69905 & Hemoglobin subunit alpha & 13598.42 & 54.93 \\
\hline P68871 & Hemoglobin subunit beta & 18402.54 & 89.80 \\
\hline P02042 & Hemoglobin subunit delta & 5838.89 & 63.95 \\
\hline P02100 & Hemoglobin subunit epsilon & 3895.00 & 6.80 \\
\hline P69891 & Hemoglobin subunit gamma-1 & 3895.00 & 6.80 \\
\hline P69892 & Hemoglobin subunit gamma-2 & 3895.00 & 6.80 \\
\hline P15515 & Histatin-1 & 16204.54 & 36.84 \\
\hline P15516 & Histatin-3 & 2631.50 & 13.73 \\
\hline Q16695 & Histone H3.1t & 524.06 & 23.53 \\
\hline Q05469 & Hormone-sensitive lipase & 43.68 & 5.30 \\
\hline Q4G0P3 & Hydrocephalus-inducing protein homolog & 15.21 & 1.93 \\
\hline A0A0G2JMB2 & Ig alpha-2 chain $\mathrm{C}$ region (Fragment) & 43004.29 & 79.12 \\
\hline A0A0A0MS07 & Ig gamma-1 chain $\mathrm{C}$ region (Fragment) & 2528.80 & 42.37 \\
\hline A0A087WYJ9 & $\lg$ mu chain $\mathrm{C}$ region & 4012.85 & 48.67 \\
\hline P04220 & Ig mu heavy chain disease protein & 3190.64 & 37.85 \\
\hline P01876 & Immunoglobulin heavy constant alpha 1 & 38140.46 & 73.65 \\
\hline P01877 & Immunoglobulin heavy constant alpha 2 & 32255.84 & 65.29 \\
\hline P01857 & Immunoglobulin heavy constant gamma 1 & 4336.06 & 47.88 \\
\hline P01859 & Immunoglobulin heavy constant gamma 2 & 1181.17 & 37.42 \\
\hline P01860 & Immunoglobulin heavy constant gamma 3 & 1276.14 & 14.59 \\
\hline P01861 & Immunoglobulin heavy constant gamma 4 & 1489.84 & 38.23 \\
\hline P01871 & Immunoglobulin heavy constant mu & 4017.99 & 50.33 \\
\hline A0A075B7F0 & Immunoglobulin heavy variable 3/OR16-10 (non-functional) (Fragment) & 299.80 & 9.48 \\
\hline A0A075B7B8 & Immunoglobulin heavy variable 3/OR16-12 (non-functional) (Fragment) & 242.49 & 9.40 \\
\hline A0A075B7E8 & Immunoglobulin heavy variable 3/OR16-13 (non-functional) (Fragment) & 242.49 & 9.40 \\
\hline S4R460 & Immunoglobulin heavy variable 3/OR16-9 (non-functional) & 5489.71 & 31.25 \\
\hline P01762 & Immunoglobulin heavy variable 3-11 & 299.80 & 9.40 \\
\hline P01766 & Immunoglobulin heavy variable 3-13 & 299.80 & 9.48 \\
\hline A0A0C4DH32 & Immunoglobulin heavy variable 3-20 (Fragment) & 299.80 & 9.40 \\
\hline A0A0B4J1V1 & Immunoglobulin heavy variable 3-21 & 299.80 & 9.40 \\
\hline P01764 & Immunoglobulin heavy variable 3-23 & 242.49 & 12.82 \\
\hline P01768 & Immunoglobulin heavy variable 3-30 & 242.49 & 31.62 \\
\hline P01772 & Immunoglobulin heavy variable 3-33 & 242.49 & 31.62 \\
\hline A0A0B4J1X8 & Immunoglobulin heavy variable 3-43 & 299.80 & 9.32 \\
\hline P01763 & Immunoglobulin heavy variable 3-48 & 299.80 & 9.40 \\
\hline P01767 & Immunoglobulin heavy variable 3-53 & 242.49 & 12.93 \\
\hline A0A0C4DH42 & Immunoglobulin heavy variable 3-66 & 242.49 & 12.93 \\
\hline P01780 & Immunoglobulin heavy variable 3-7 & 299.80 & 9.40 \\
\hline A0A0B4J1X5 & Immunoglobulin heavy variable 3-74 & 242.49 & 9.40 \\
\hline P01782 & Immunoglobulin heavy variable 3-9 & 299.80 & 9.32 \\
\hline P01591 & Immunoglobulin J chain & 20006.96 & 49.06 \\
\hline P01834 & Immunoglobulin kappa constant & 28856.88 & 82.24 \\
\hline A0A0C4DH90 & Immunoglobulin kappa variable 3/OR2-268 (non-functional) (Fragment) & 362.90 & 7.76 \\
\hline P04433 & Immunoglobulin kappa variable 3-11 & 1198.54 & 26.09 \\
\hline P01624 & Immunoglobulin kappa variable 3-15 & 362.90 & 7.83 \\
\hline A0A075B6H7 & Immunoglobulin kappa variable 3-7 (non-functional) (Fragment) & 362.90 & 7.76 \\
\hline AOAOAOMRZ8 & Immunoglobulin kappa variable 3D-11 & 1198.54 & 26.09 \\
\hline A0A0C4DH55 & Immunoglobulin kappa variable 3D-7 & 362.90 & 7.56 \\
\hline P06312 & Immunoglobulin kappa variable 4-1 & 250.98 & 19.83 \\
\hline P0CG04 & Immunoglobulin lambda constant 1 & 40610.55 & 77.36 \\
\hline PODOY2 & Immunoglobulin lambda constant 2 & 44714.51 & 93.40 \\
\hline PODOY3 & Immunoglobulin lambda constant 3 & 44714.51 & 93.40 \\
\hline
\end{tabular}

Continued on the next page 
Continued from previous page

\begin{tabular}{|c|c|c|c|}
\hline P0CF74 & Immunoglobulin lambda constant 6 & 23147.62 & 50.94 \\
\hline A0M8Q6 & Immunoglobulin lambda constant 7 & 19435.36 & 36.79 \\
\hline P01715 & Immunoglobulin lambda variable 3-1 & 344.58 & 38.26 \\
\hline B9A064 & Immunoglobulin lambda-like polypeptide 5 & 40610.55 & 38.32 \\
\hline Q9BQU0 & Inhibitory NK receptor & 242.62 & 11.21 \\
\hline Q9NVH2 & Integrator complex subunit 7 & 267.39 & 4.26 \\
\hline Q01638 & Interleukin-1 receptor-like 1 & 304.24 & 7.01 \\
\hline HOYNL8 & Iron-responsive element-binding protein 2 & 377.91 & 29.09 \\
\hline A0A0G2JPA6 & Killer cell immunoglobulin-like receptor 3DL2 & 242.62 & 11.64 \\
\hline P22079 & Lactoperoxidase & 2259.91 & 35.11 \\
\hline P02788 & Lactotransferrin & 862.74 & 28.59 \\
\hline A6NMS7 & Leucine-rich repeat-containing protein $37 \mathrm{~A}$ & 263.12 & 1.71 \\
\hline A6NM11 & Leucine-rich repeat-containing protein $37 \mathrm{~A} 2$ & 252.18 & 1.71 \\
\hline 060309 & Leucine-rich repeat-containing protein $37 \mathrm{~A} 3$ & 276.06 & 4.53 \\
\hline P31025 & Lipocalin-1 & 14925.97 & 53.98 \\
\hline Q86W92 & Liprin-beta-1 & 292.75 & 10.29 \\
\hline P00338 & L-lactate dehydrogenase $\mathrm{A}$ chain & 196.57 & 21.69 \\
\hline Q9BY66 & Lysine-specific demethylase 5D & 307.10 & 8.58 \\
\hline P61626 & Lysozyme C & 15283.53 & 66.89 \\
\hline P14174 & Macrophage migration inhibitory factor & 616.56 & 47.83 \\
\hline C9JJ79 & Malate dehydrogenase (Fragment) & 263.72 & 11.71 \\
\hline P40925 & Malate dehydrogenase_cytoplasmic & 653.55 & 11.38 \\
\hline Q5HYA8 & Meckelin & 241.84 & 1.61 \\
\hline Q9Y4B5 & Microtubule cross-linking factor 1 & 26.23 & 1.52 \\
\hline Q8TAX7 & Mucin-7 & 13700.40 & 9.28 \\
\hline U3KPS2 & Myeloblastin & 554.69 & 17.67 \\
\hline P24158 & Myeloblastin & 631.43 & 28.52 \\
\hline Q9NYA4 & Myotubularin-related protein 4 & 315.44 & 7.11 \\
\hline P59665 & Neutrophil defensin 1 & 1789.52 & 25.53 \\
\hline P59666 & Neutrophil defensin 3 & 1789.52 & 25.53 \\
\hline Q9BYH8 & NF-kappa-B inhibitor zeta & 371.15 & 4.32 \\
\hline Q2L696 & Nucb2 splice variant & 663.95 & 25.13 \\
\hline A0A087WSV8 & Nucleobindin 2_isoform CRA_b & 954.67 & 25.48 \\
\hline P80303 & Nucleobindin-2 & 954.67 & 25.48 \\
\hline P04746 & Pancreatic alpha-amylase & 88276.59 & 55.97 \\
\hline P42338 & Phosphatidylinositol 4_5-bisphosphate 3-kinase catalytic subunit beta isoform & 561.79 & 6.26 \\
\hline AOAOAOMRF9 & Phosphoinositide phospholipase C & 313.90 & 4.55 \\
\hline P13796 & Plastin-2 & 283.93 & 25.04 \\
\hline Q86YL7 & Podoplanin & 866.94 & 34.57 \\
\hline P11940 & Polyadenylate-binding protein 1 & 582.59 & 10.69 \\
\hline E7ERJ7 & Polyadenylate-binding protein & 582.59 & 11.26 \\
\hline Q8NDX5 & Polyhomeotic-like protein 3 & 348.42 & 3.05 \\
\hline P01833 & Polymeric immunoglobulin receptor & 12791.93 & 57.98 \\
\hline Q8TCS8 & Polyribonucleotide nucleotidyltransferase 1_mitochondrial & 32.49 & 3.19 \\
\hline Q6S8J3 & POTE ankyrin domain family member $\mathrm{E}$ & 4118.47 & 13.86 \\
\hline A5A3E0 & POTE ankyrin domain family member $F$ & 4040.70 & 11.72 \\
\hline P0CG38 & POTE ankyrin domain family member I & 3413.22 & 4.74 \\
\hline P0CG39 & POTE ankyrin domain family member $\mathrm{J}$ & 2796.68 & 3.85 \\
\hline Q8TED1 & Probable glutathione peroxidase 8 & 341.42 & 17.22 \\
\hline Q8IZM9 & Probable sodium-coupled neutral amino acid transporter 6 & 426.92 & 6.80 \\
\hline K7EJ44 & Profilin & 470.78 & 37.50 \\
\hline P07737 & Profilin-1 & 910.82 & 49.29 \\
\hline P12273 & Prolactin-inducible protein & 30448.27 & 76.71 \\
\hline АОАОАОМТЗ1 & Proline-rich protein 4 & 23475.68 & 72.29 \\
\hline P07602 & Prosaposin & 510.46 & 39.12 \\
\hline Q5W0V3 & Protein FAM160B1 & 862.81 & 23.66 \\
\hline Q6P5S2 & Protein LEG1 homolog & 6592.09 & 36.97 \\
\hline Q9H7Z3 & Protein NRDE2 homolog & 45.79 & 1.20 \\
\hline P05109 & Protein S100-A8 & 3184.30 & 23.66 \\
\hline
\end{tabular}

Continued on the next page 
Continued from previous page

\begin{tabular}{|c|c|c|c|}
\hline P06702 & Protein S100-A9 & 1737.55 & 77.19 \\
\hline O14795 & Protein unc-13 homolog B & 59.05 & 1.19 \\
\hline H3BQ60 & Puratrophin-1 (Fragment) & 266.79 & 50.00 \\
\hline Q9BYX7 & Putative beta-actin-like protein 3 & 2063.16 & 10.67 \\
\hline Q5VSP4 & Putative lipocalin 1-like protein 1 & 3097.31 & 11.11 \\
\hline P52566 & Rho GDP-dissociation inhibitor 2 & 1026.87 & 30.35 \\
\hline P35913 & Rod cGMP-specific 3'_5'-cyclic phosphodiesterase subunit beta & 374.14 & 8.08 \\
\hline P02810 & Salivary acidic proline-rich phosphoprotein $1 / 2$ & 4566.91 & 72.29 \\
\hline P02787 & Serotransferrin & 4566.92 & 48.42 \\
\hline P02768 & Serum albumin & 63281.61 & 75.04 \\
\hline O00193 & Small acidic protein & 258.69 & 13.11 \\
\hline P02808 & Statherin & 41653.6 & 48.39 \\
\hline P02814 & Submaxillary gland androgen-regulated protein 3B & 20898.6 & 65.82 \\
\hline Q9UH99 & SUN domain-containing protein 2 & 70.82 & 1.67 \\
\hline A0A075B6V5 & T cell receptor alpha variable 36/delta variable 7 (Fragment) & 278.89 & 24.78 \\
\hline Q7Z6L1 & Tectonin beta-propeller repeat-containing protein 1 & 384.23 & 7.12 \\
\hline $\mathrm{F} 2 \mathrm{Z} 350$ & Testis-expressed protein 29 & 447.37 & 32.14 \\
\hline Q7Z4L5 & Tetratricopeptide repeat protein 21B & 78.57 & 4.56 \\
\hline P20061 & Transcobalamin-1 & 378.51 & 22.86 \\
\hline P29401 & Transketolase & 676.10 & 30.98 \\
\hline Q6ZMR5 & Transmembrane protease serine $11 \mathrm{~A}$ & 281.15 & 11.16 \\
\hline P02766 & Transthyretin & 438.46 & 44.22 \\
\hline P60174 & Triosephosphate isomerase & 651.56 & 36.36 \\
\hline O43818 & U3 small nucleolar RNA-interacting protein 2 & 297.84 & 16.00 \\
\hline A0A0J9YY99 & Uncharacterized protein (Fragment) & 242.49 & 12.82 \\
\hline H7C2Y3 & Uncharacterized protein C2orf80 (Fragment) & 318.87 & 16.41 \\
\hline H0Y8H3 & Uncharacterized protein C3orf67 (Fragment) & 590.54 & 74.68 \\
\hline A0A087WZY1 & Uncharacterized protein & 22581.8 & 16.60 \\
\hline A0A0G2JMZ2 & Uncharacterized protein & 252.18 & 1.71 \\
\hline A0A0G2JRT3 & Uncharacterized protein & 252.18 & 1.77 \\
\hline P02774 & Vitamin D-binding protein & 245.21 & 21.52 \\
\hline Q14508 & WAP four-disulfide core domain protein 2 & 935.99 & 33.87 \\
\hline Q9UDV6 & Zinc finger protein 212 & 424.39 & 16.97 \\
\hline P25311 & Zinc-alpha-2-glycoprotein & 2292.60 & 31.54 \\
\hline Q96DA0 & Zymogen granule protein 16 homolog B & 46355.09 & 58.17 \\
\hline
\end{tabular}

individual variation. The analysis of individual samples is important to allow confident comparison among the groups under study, especially in quantitative shotgun proteomics.

Generally, the methodologies used in proteomics are classified into two main categories: the bottom-up, which is also called shotgun proteomics, or top-down proteomics. Both methodologies have advantages and limitations, and their employment depends on the treatment given to the sample ${ }^{9}$. Shotgun proteomics is characterized by analyzing samples after proteolytic digestion in peptides, which is typically performed with trypsin ${ }^{2,9}$, while the top-down proteome of a sample involves analysis of intact proteins ${ }^{9}$. In shotgun proteomics, proteins from a complex mixture are digested, and the resulting peptides are analyzed by mass spectrometry. One of the advantages of this strategy is to investigate a large number of proteins regardless of their size. The limitations are related to incomplete coverage of the protein sequence, loss of post-translational modifications and degradation because of proteolytic digestion ${ }^{4,9}$. The top-down proteomics differs from the shotgun as it explores intact proteins by injecting the proteins into the mass spectrometer without performing digestion, minimizing any change in the sample and allowing a better characterization of post-translational modifications, especially those related to naturally occurring cleavages and alternative splicing ${ }^{3}$, avoiding interference problems based on peptides and allowing deducing the primary structure of the protein ${ }^{4,9}$. However, this technique is considered bounded by the collision energy required in protein fragmentation, which is insufficient for proteins greater than $50 \mathrm{KDa}$, and its application is restricted to the analysis of purified proteins ${ }^{4,9,11}$. In addition, top-down proteomics method requires the use of one or more forms of separation prior to mass spectrometry analysis ${ }^{12}$. Moreover, top-down platforms are intrinsically limited by the sample treatments required for use in mass 
Table 4- Proteins of the saliva identified in only in the individual analysis

\begin{tabular}{|c|c|c|c|}
\hline Accession number & Protein name & score & Cover(\%) \\
\hline P31947 & 14-3-3 protein sigma & 297.17 & 24.60 \\
\hline O00231 & $26 \mathrm{~S}$ proteasome non-ATPase regulatory subunit 11 & 453.07 & 10.66 \\
\hline P68032 & Actin_alpha cardiac muscle 1 & 7799.84 & 26.53 \\
\hline P68133 & Actin_alpha skeletal muscle & 7799.84 & 26.53 \\
\hline P62736 & Actin_aortic smooth muscle & 7555.95 & 23.61 \\
\hline P60709 & Actin_cytoplasmic 1 & 17763.84 & 65.60 \\
\hline P63261 & Actin_cytoplasmic 2 & 17763.84 & 65.60 \\
\hline P63267 & Actin_gamma-enteric smooth muscle & 7555.95 & 23.67 \\
\hline Q0VD77 & ADAMTS-like protein 5 & 410.00 & 32.06 \\
\hline P00813 & Adenosine deaminase & 350.67 & 12.67 \\
\hline 060503 & Adenylate cyclase type 9 & 471.53 & 5.69 \\
\hline Q99996 & A-kinase anchor protein 9 & 34.16 & 3.58 \\
\hline C9JKR2 & Albumin_isoform CRA_k & 29220.48 & 74.82 \\
\hline P01009 & Alpha-1-antitrypsin & 413.67 & 11.24 \\
\hline P01023 & Alpha-2-macroglobulin & 445.71 & 15.33 \\
\hline A8K2U0 & Alpha-2-macroglobulin-like protein 1 & 148.51 & 10.32 \\
\hline P04745 & Alpha-amylase 1 & 97076.24 & 78.86 \\
\hline P19961 & Alpha-amylase 2B & 77429.32 & 62.82 \\
\hline P06733 & Alpha-enolase & 1439.59 & 49.08 \\
\hline Q8N6M6 & Aminopeptidase $\mathrm{O}$ & 261.58 & 10.13 \\
\hline Q01484 & Ankyrin-2 & 39.24 & 4.22 \\
\hline P02652 & Apolipoprotein A-II & 941.64 & 47.00 \\
\hline Q14562 & ATP-dependent RNA helicase DHX8 & 365.21 & 7.38 \\
\hline Q8IYB8 & ATP-dependent RNA helicase SUPV3L1_ mitochondrial & 331.22 & 7.00 \\
\hline P04280 & Basic salivary proline-rich protein 1 & 8867.97 & 44.39 \\
\hline P02812 & Basic salivary proline-rich protein 2 & 54196.77 & 69.71 \\
\hline I3L192 & Basigin (Fragment) & 185.70 & 16.88 \\
\hline P61769 & Beta-2-microglobulin & 2754.07 & 54.62 \\
\hline Q562R1 & Beta-actin-like protein 2 & 1943.05 & 10.90 \\
\hline P13929 & Beta-enolase & 131.58 & 7.60 \\
\hline 095342 & Bile salt export pump & 495.58 & 8.18 \\
\hline Q96DR5 & BPI fold-containing family A member 2 & 6426.16 & 43.37 \\
\hline Q8N4F0 & BPI fold-containing family B member 2 & 6613.00 & 37.99 \\
\hline Q9NQY0 & Bridging integrator 3 & 398.03 & 11.46 \\
\hline Q8N4G4 & CA6 protein & 294.75 & 4.47 \\
\hline 075808 & Calpain-15 & 215.66 & 3.68 \\
\hline P23280 & Carbonic anhydrase 6 & 9824.04 & 57.47 \\
\hline Q0P665 & CCDC88C protein & 188.41 & 0.00 \\
\hline Q8N163 & Cell cycle and apoptosis regulator protein 2 & 573.49 & 11.05 \\
\hline O14647 & Chromodomain-helicase-DNA-binding protein 2 & 250.16 & 2.84 \\
\hline H0Y7A8 & Chromosome 9 open reading frame 3 (Fragment) & 236.18 & 19.31 \\
\hline P35606 & Coatomer subunit beta' & 189.71 & 2.21 \\
\hline $\mathrm{A} 2 \mathrm{ABG} 0$ & Complement C2 (Fragment) & 409.38 & 20.25 \\
\hline P01024 & Complement C3 & 526.68 & 24.53 \\
\hline Q53SF7 & Cordon-bleu protein-like 1 & 168.78 & 4.32 \\
\hline P04080 & Cystatin-B & 1041.42 & 70.41 \\
\hline P01034 & Cystatin-C & 3437.76 & 51.37 \\
\hline P28325 & Cystatin-D & 2141.16 & 75.35 \\
\hline P01036 & Cystatin-S & 28189.63 & 76.60 \\
\hline P09228 & Cystatin-SA & 13641.19 & 67.38 \\
\hline P01037 & Cystatin-SN & 28293.31 & 70.21 \\
\hline P54108 & Cysteine-rich secretory protein 3 & 373.11 & 34.29 \\
\hline Q8NF50 & Dedicator of cytokinesis protein 8 & 351.74 & 5.72 \\
\hline Q9UGM3 & Deleted in malignant brain tumors 1 protein & 285.95 & 7.05 \\
\hline Q5TBH6 & Dihydroxyacetone phosphate acyltransferase (Fragment) & 182.78 & 23.42 \\
\hline P28340 & DNA polymerase delta catalytic subunit & 269.07 & 5.15 \\
\hline M0R2B7 & DNA polymerase & 269.07 & 5.03 \\
\hline Q5T4S7 & E3 ubiquitin-protein ligase UBR4 & 22.83 & 2.70 \\
\hline
\end{tabular}

Continued on the next page 
Continued from previous page

\begin{tabular}{|c|c|c|c|}
\hline Q92838 & Ectodysplasin-A & 258.64 & 15.86 \\
\hline Q8N3D4 & EH domain-binding protein 1-like protein 1 & 260.45 & 4.33 \\
\hline Q6P179 & Endoplasmic reticulum aminopeptidase 2 & 522.88 & 7.92 \\
\hline Q7L775 & EPM2A-interacting protein 1 & 277.97 & 2.80 \\
\hline Q9H501 & ESF1 homolog & 205.30 & 12.22 \\
\hline A0A1B0GUN9 & Espin & 59.79 & 6.02 \\
\hline Q8IXL6 & Extracellular serine/threonine protein kinase FAM20C & 322.36 & 5.48 \\
\hline Q01469 & Fatty acid-binding protein_epidermal & 444.20 & 32.59 \\
\hline Q9BZK7 & F-box-like/WD repeat-containing protein TBL1XR1 & 376.57 & 15.18 \\
\hline P02675 & Fibrinogen beta chain & 187.44 & 13.03 \\
\hline P15328 & Folate receptor alpha & 400.38 & 35.80 \\
\hline Q8NHY3 & GAS2-like protein 2 & 287.31 & 6.14 \\
\hline P06396 & Gelsolin & 427.99 & 17.77 \\
\hline 014893 & Gem-associated protein 2 & 443.14 & 31.07 \\
\hline P53611 & Geranylgeranyl transferase type- 2 subunit beta & 470.85 & 16.92 \\
\hline P06744 & Glucose-6-phosphate isomerase & 787.26 & 28.49 \\
\hline P04406 & Glyceraldehyde-3-phosphate dehydrogenase & 793.86 & 39.40 \\
\hline 095427 & GPI ethanolamine phosphate transferase 1 & 233.92 & 7.73 \\
\hline Q8IWJ2 & GRIP and coiled-coil domain-containing protein 2 & 22.31 & 1.25 \\
\hline P00738 & Haptoglobin & 1233.11 & 55.42 \\
\hline P00739 & Haptoglobin-related protein & 281.28 & 15.52 \\
\hline G3V1N2 & HCG1745306_isoform CRA_a & 15851.36 & 94.55 \\
\hline E7BWR8 & HCG2043595_isoform CRA_a & 252.74 & 7.76 \\
\hline P69905 & Hemoglobin subunit alpha & 16443.62 & 83.80 \\
\hline P68871 & Hemoglobin subunit beta & 22740.65 & 95.24 \\
\hline P02042 & Hemoglobin subunit delta & 5150.58 & 39.46 \\
\hline P02100 & Hemoglobin subunit epsilon & 2097.61 & 6.80 \\
\hline P69891 & Hemoglobin subunit gamma-1 & 2097.61 & 6.80 \\
\hline P69892 & Hemoglobin subunit gamma-2 & 2097.61 & 6.80 \\
\hline P15515 & Histatin-1 & 5208.41 & 36.84 \\
\hline P15516 & Histatin-3 & 4795.66 & 13.73 \\
\hline E9PRF4 & Histone-lysine N-methyltransferase (Fragment) & 316.72 & 3.89 \\
\hline Q15047 & Histone-lysine N-methyltransferase SETDB1 & 316.72 & 3.80 \\
\hline P47902 & Homeobox protein CDX-1 & 196.38 & 26.04 \\
\hline P31270 & Homeobox protein Hox-A11 & 264.91 & 14.38 \\
\hline P09630 & Homeobox protein Hox-C6 & 93.47 & 4.68 \\
\hline Q4G0P3 & Hydrocephalus-inducing protein homolog & 264.63 & 2.46 \\
\hline A0A0G2JMB2 & Ig alpha- 2 chain $C$ region (Fragment) & 48303.27 & 79.12 \\
\hline A0A0A0MS07 & Ig gamma- 1 chain $\mathrm{C}$ region (Fragment) & 3209.86 & 45.76 \\
\hline A0A087WYJ9 & $\lg$ mu chain $\mathrm{C}$ region & 3019.36 & 54.87 \\
\hline P04220 & Ig mu heavy chain disease protein & 2170.36 & 39.90 \\
\hline P01876 & Immunoglobulin heavy constant alpha 1 & 40927.72 & 84.42 \\
\hline P01877 & Immunoglobulin heavy constant alpha 2 & 28394.92 & 68.53 \\
\hline P01857 & Immunoglobulin heavy constant gamma 1 & 5891.82 & 50.91 \\
\hline P01859 & Immunoglobulin heavy constant gamma 2 & 1360.10 & 31.29 \\
\hline P01860 & Immunoglobulin heavy constant gamma 3 & 1756.61 & 30.24 \\
\hline P01861 & Immunoglobulin heavy constant gamma 4 & 1509.92 & 30.89 \\
\hline P01871 & Immunoglobulin heavy constant mu & 3019.36 & 54.75 \\
\hline A0A075B7D0 & Immunoglobulin heavy variable 1/OR15-1 (non-functional) (Fragment) & 252.28 & 10.26 \\
\hline A0A075B7F0 & Immunoglobulin heavy variable 3/OR16-10 (non-functional) (Fragment) & 3426.81 & 13.79 \\
\hline S4R460 & Immunoglobulin heavy variable 3/OR16-9 (non-functional) & 8502.51 & 36.46 \\
\hline P01762 & Immunoglobulin heavy variable $3-11$ & 3426.81 & 23.08 \\
\hline P01766 & Immunoglobulin heavy variable $3-13$ & 3426.81 & 13.79 \\
\hline A0A0C4DH32 & Immunoglobulin heavy variable 3-20 (Fragment) & 3426.81 & 13.68 \\
\hline A0A0B4J1V1 & Immunoglobulin heavy variable 3-21 & 3426.81 & 23.08 \\
\hline A0A0B4J1X8 & Immunoglobulin heavy variable $3-43$ & 3426.81 & 13.56 \\
\hline P01763 & Immunoglobulin heavy variable $3-48$ & 3426.81 & 23.08 \\
\hline P01780 & Immunoglobulin heavy variable 3-7 & 3426.81 & 23.08 \\
\hline P01782 & Immunoglobulin heavy variable 3-9 & 3426.81 & 13.56 \\
\hline
\end{tabular}

Continued on the next page 
Continued from previous page

\begin{tabular}{|c|c|c|c|}
\hline A0A0B4J1U7 & Immunoglobulin heavy variable 6-1 & 294.24 & 5.79 \\
\hline P01591 & Immunoglobulin $\mathrm{J}$ chain & 21280.25 & 68.55 \\
\hline P01834 & Immunoglobulin kappa constant & 37053.21 & 85.98 \\
\hline P04433 & Immunoglobulin kappa variable 3-11 & 1303.48 & 26.09 \\
\hline P01619 & Immunoglobulin kappa variable 3-20 & 868.06 & 7.76 \\
\hline AOAOAOMRZ8 & Immunoglobulin kappa variable 3D-11 & 1303.48 & 26.09 \\
\hline P06312 & Immunoglobulin kappa variable 4-1 & 423.92 & 19.83 \\
\hline P0CG04 & Immunoglobulin lambda constant 1 & 33910.90 & 77.36 \\
\hline PODOY2 & Immunoglobulin lambda constant 2 & 40674.07 & 77.36 \\
\hline P0DOY3 & Immunoglobulin lambda constant 3 & 40674.07 & 77.36 \\
\hline P0CF74 & Immunoglobulin lambda constant 6 & 30147.40 & 50.94 \\
\hline A0M8Q6 & Immunoglobulin lambda constant 7 & 22557.57 & 36.79 \\
\hline B9A064 & Immunoglobulin lambda-like polypeptide 5 & 33910.9 & 38.32 \\
\hline P06870 & Kallikrein-1 & 196.20 & 10.31 \\
\hline P43626 & Killer cell immunoglobulin-like receptor 2DL1 & 252.74 & 7.76 \\
\hline A0A0G2JNJ6 & Killer cell immunoglobulin-like receptor 2DS1 & 325.76 & 16.62 \\
\hline Q9HAQ2 & Kinesin-like protein KIF9 & 158.59 & 4.43 \\
\hline B4DZK5 & Kinesin-like protein & 133.37 & 10.51 \\
\hline $\mathrm{Q} 6 \mathrm{H} 2 \mathrm{H} 3$ & KIR2DL1 & 252.74 & 7.76 \\
\hline P22079 & Lactoperoxidase & 1577.03 & 41.43 \\
\hline P02788 & Lactotransferrin & 1069.99 & 35.21 \\
\hline Q6PKG0 & La-related protein 1 & 139.16 & 6.20 \\
\hline P09960 & Leukotriene A-4 hydrolase & 225.55 & 19.31 \\
\hline P31025 & Lipocalin-1 & 8361.36 & 51.14 \\
\hline P00338 & L-lactate dehydrogenase $\mathrm{A}$ chain & 986.52 & 20.78 \\
\hline Q9BYZ2 & L-lactate dehydrogenase A-like 6B & 323.86 & 8.66 \\
\hline Q9BY66 & Lysine-specific demethylase 5D & 59.78 & 0.78 \\
\hline P61626 & Lysozyme C & 9288.56 & 54.05 \\
\hline P14174 & Macrophage migration inhibitory factor & 254.18 & 55.65 \\
\hline P14780 & Matrix metalloproteinase- 9 & 225.62 & 15.13 \\
\hline Q96JG8 & Melanoma-associated antigen D4 & 150.96 & 6.07 \\
\hline P01033 & Metalloproteinase inhibitor 1 & 445.25 & 29.95 \\
\hline Q96GX9 & Methylthioribulose-1-phosphate dehydratase & 198.99 & 23.14 \\
\hline O15021 & Microtubule-associated serine/threonine-protein kinase 4 & 168.04 & 3.43 \\
\hline O43283 & Mitogen-activated protein kinase kinase kinase 13 & 533.35 & 8.70 \\
\hline Q8TAX7 & Mucin-7 & 10429.01 & 15.65 \\
\hline Q8NI22 & Multiple coagulation factor deficiency protein 2 & 260.43 & 23.97 \\
\hline O75970 & Multiple PDZ domain protein & 43.13 & 2.32 \\
\hline P24158 & Myeloblastin & 341.23 & 17.19 \\
\hline P59665 & Neutrophil defensin 1 & 2353.04 & 15.96 \\
\hline P59666 & Neutrophil defensin 3 & 2353.04 & 15.96 \\
\hline P04746 & Pancreatic alpha-amylase & 64829.77 & 60.27 \\
\hline Q08752 & Peptidyl-prolyl cis-trans isomerase D & 470.08 & 17.57 \\
\hline P13796 & Plastin-2 & 531.41 & 28.87 \\
\hline P01833 & Polymeric immunoglobulin receptor & 16305.42 & 45.42 \\
\hline Q6S8J3 & POTE ankyrin domain family member $E$ & 3659.07 & 9.49 \\
\hline A5А3Е0 & POTE ankyrin domain family member $F$ & 3575.10 & 10.14 \\
\hline P0CG38 & POTE ankyrin domain family member I & 2591.40 & 5.67 \\
\hline P0CG39 & POTE ankyrin domain family member $\mathrm{J}$ & 1362.79 & 4.82 \\
\hline P17844 & Probable ATP-dependent RNA helicase DDX5 & 220.36 & 4.89 \\
\hline I3L3D5 & Profilin (Fragment) & 1209.81 & 10.91 \\
\hline P07737 & Profilin-1 & 1209.81 & 20.71 \\
\hline $\mathrm{P} 12273$ & Prolactin-inducible protein & 22984.41 & 89.04 \\
\hline АОАОАОМТ31 & Proline-rich protein 4 & 52615.69 & 72.29 \\
\hline P07602 & Prosaposin & 316.92 & 22.52 \\
\hline Q9P219 & Protein Daple & 206.07 & 0.69 \\
\hline P49354 & Protein farnesyltransferase/geranylgeranyltransferase type-1 subunit alpha & 1184.15 & 17.41 \\
\hline Q6P5S2 & Protein LEG1 homolog & 7928.19 & 40.00 \\
\hline Q9H7Z3 & Protein NRDE2 homolog & 339.41 & 6.79 \\
\hline
\end{tabular}

Continued on the next page 
Continued from previous page

\begin{tabular}{|c|c|c|c|}
\hline Q8WYL5 & Protein phosphatase Slingshot homolog 1 & 286.92 & 2.38 \\
\hline 043663 & Protein regulator of cytokinesis 1 & 83.55 & 7.42 \\
\hline P05109 & Protein S100-A8 & 1391.46 & 31.18 \\
\hline P06702 & Protein S100-A9 & 2043.00 & 78.07 \\
\hline Q9NQW1 & Protein transport protein Sec31B & 442.02 & 7.63 \\
\hline Q92954 & Proteoglycan 4 & 188.50 & 2.78 \\
\hline Q96MK3 & Pseudokinase FAM20A & 287.95 & 8.50 \\
\hline Q9BYX7 & Putative beta-actin-like protein 3 & 1353.87 & 29.07 \\
\hline Q5VSP4 & Putative lipocalin 1-like protein 1 & 3095.80 & 11.11 \\
\hline Q5JXB2 & Putative ubiquitin-conjugating enzyme E2 N-like & 341.70 & 32.03 \\
\hline A4QN01 & Putative uncharacterized protein encoded by LINC01553 & 191.02 & 19.53 \\
\hline Q15276 & Rab GTPase-binding effector protein 1 & 211.79 & 8.58 \\
\hline Q9Y2J0 & Rabphilin-3A & 47.85 & 7.93 \\
\hline Q14699 & Raftlin & 796.05 & 17.30 \\
\hline G3XAJ6 & Raft-linking protein_isoform CRA_c & 779.81 & 13.84 \\
\hline P52565 & Rho GDP-dissociation inhibitor 1 & 251.72 & 19.61 \\
\hline Q8IXT5 & RNA-binding protein $12 \mathrm{~B}$ & 263.79 & 6.39 \\
\hline K4DI92 & RWD domain containing $4 \mathrm{~A}$ & 636.75 & 30.48 \\
\hline Q6NW29 & RWD domain-containing protein 4 & 636.75 & 30.32 \\
\hline P02810 & Salivary acidic proline-rich phosphoprotein $1 / 2$ & 52615.69 & 72.29 \\
\hline Q9BZL6 & Serine/threonine-protein kinase D2 & 403.28 & 9.68 \\
\hline B4DTS2 & Serine/threonine-protein kinase & 401.26 & 9.57 \\
\hline P02787 & Serotransferrin & 4390.41 & 39.26 \\
\hline P02768 & Serum albumin & 64055.35 & 79.80 \\
\hline P02808 & Statherin & 25654.54 & 48.39 \\
\hline P02814 & Submaxillary gland androgen-regulated protein $3 \mathrm{~B}$ & 50678.11 & 65.82 \\
\hline P00441 & Superoxide dismutase [Cu-Zn] & 1005.47 & 45.45 \\
\hline HOYN01 & Talin-2 & 197.30 & 34.55 \\
\hline Q92609 & TBC1 domain family member 5 & 344.39 & 5.16 \\
\hline Q7Z6L1 & Tectonin beta-propeller repeat-containing protein 1 & 62.51 & 2.49 \\
\hline Q6N022 & Teneurin-4 & 64.41 & 4.15 \\
\hline P10599 & Thioredoxin & 300.36 & 32.38 \\
\hline Q96J01 & THO complex subunit 3 & 335.46 & 20.51 \\
\hline Q5JTD0 & Tight junction-associated protein 1 & 432.54 & 3.95 \\
\hline P37837 & Transaldolase & 676.70 & 23.74 \\
\hline P20061 & Transcobalamin-1 & 670.49 & 33.26 \\
\hline $\mathrm{A} 6 \mathrm{H} 8 \mathrm{Y} 1$ & Transcription factor TFIIIB component B" homolog & 67.01 & 6.17 \\
\hline P29401 & Transketolase & 1109.18 & 29.05 \\
\hline Q9C0B7 & Transport and Golgi organization protein 6 homolog & 101.09 & 8.78 \\
\hline P60174 & Triosephosphate isomerase & 582.07 & 15.73 \\
\hline P07437 & Tubulin beta chain & 251.86 & 5.86 \\
\hline Q13885 & Tubulin beta-2A chain & 268.91 & 5.84 \\
\hline Q9BVA1 & Tubulin beta-2B chain & 251.86 & 5.84 \\
\hline P04350 & Tubulin beta- $4 \mathrm{~A}$ chain & 242.62 & 5.86 \\
\hline P68371 & Tubulin beta-4B chain & 242.62 & 5.84 \\
\hline H3BLT7 & Tubulin monoglycylase TTLL3 (Fragment) & 205.55 & 1.15 \\
\hline Q9NVE5 & Ubiquitin carboxyl-terminal hydrolase 40 & 49.55 & 6.15 \\
\hline Q70EL2 & Ubiquitin carboxyl-terminal hydrolase 45 & 709.84 & 12.04 \\
\hline D6RC01 & Ubiquitinyl hydrolase 1 & 685.20 & 10.14 \\
\hline B4DSH7 & UDP-galactose translocator & 296.27 & 22.16 \\
\hline $\mathrm{H} 7 \mathrm{C} 2 \mathrm{Y} 3$ & Uncharacterized protein C2orf80 (Fragment) & 203.05 & 50.78 \\
\hline Q9H1L0 & Uncharacterized protein MIR1-1HG & 440.61 & 32.48 \\
\hline A0A087WZY1 & Uncharacterized protein & 50162.86 & 16.60 \\
\hline J3QRI8 & UPF0183 protein C16orf70 (Fragment) & 350.13 & 32.65 \\
\hline Q13488 & V-type proton ATPase $116 \mathrm{kDa}$ subunit a isoform 3 & 105.99 & 9.40 \\
\hline Q14508 & WAP four-disulfide core domain protein 2 & 2122.26 & 33.87 \\
\hline Q9NXC5 & WD repeat-containing protein mio & 208.07 & 1.94 \\
\hline Q9BUG6 & Zinc finger and SCAN domain-containing protein $5 \mathrm{~A}$ & 97.41 & 13.71 \\
\hline Q8N8U3 & Zinc finger $\mathrm{CCHC}$ domain-containing protein 5 & 189.02 & 7.79 \\
\hline
\end{tabular}

Continued on the next page 
Continued from previous page

\begin{tabular}{llcc}
\hline Q9H0M4 & Zinc finger CW-type PWWP domain protein 1 & 242.57 & 7.10 \\
Q9NWS9 & Zinc finger protein 446 & 77.75 & 7.56 \\
P25311 & Zinc-alpha-2-glycoprotein & 1420.80 & 28.19 \\
Q96DA0 & Zymogen granule protein 16 homolog B & 32673.11 & 56.73 \\
\hline
\end{tabular}

spectrometry, involving the use of acids such as formic and trifluoroacetic acid ${ }^{9,12,19}$, which inevitably exclude proteins that are insoluble in acidic solutions. In addition, intact high molecular weight proteins and heterogeneous glycosylated proteins are not accessible in their naturally occurring form, even to the best level of mass spectrometry ${ }^{2}$.

Previous studies demonstrated that top-down platforms cannot achieve the same coverage of shotgun platforms for different reasons, such as: i) the intact protein must be soluble in the acid solution compatible with an ESI-MS analysis; (ii) the protein should not be heterogeneous (glycosylated isoforms), because in this case the intact protein mass cannot be deduced by the ESI spectrum; (iii) protein dimensions have to be limited, because MS-MS fragmentation spectra are too complex to be interpreted ${ }^{3,15}$. Nonetheless, the topdown strategy may reveal the richness of the isoform and the diversity of post-translational modifications, which in the shotgun proteomics strategy may result in the relevant loss of this molecular information ${ }^{2,3}$. Thus, shotgun proteomics may exhibit this deficiency in the human saliva proteome, in which many proteins such as basic PRPs and acids are not very susceptible to the proteolytic enzymes action and reveal very similar sequences. Therefore, many fragments cannot be related to a specific original protein. However, the shotgun platforms showed the best performance in terms of number of components detected, because the sensitivity of mass spectrometry is sufficient to reveal thousands of peptides in a single analysis. In this way, shotgun proteomics covers the largest variety of detectable components, regardless of their mass, due to the proteolytic digestion of large proteins almost always generates peptides that can disclose the presence of the protein in a complex mixture. Due to these reasons, the number of salivary components currently detectable by shotgun proteomics approaches is more than five times greater than that of components detected by any other platform ${ }^{2,10}$. Thus, in this study we employed shotgun proteomics.

Based on the results of the two tests, the protocol for salivary shotgun proteomic analysis was satisfactory, since it allowed the identification of many proteins, including those typically found in saliva. Moreover, it is easy to perform and cheaper than the methods previously described, since it does not require the use of depletion columns. Furthermore, it allows individual analysis of the samples, which is very important in quantitative proteomics. Thus, this protocol could be used in future studies involving shotgun proteomic analysis of saliva.

\section{Acknowledgements}

The authors thank FAPESP for the concession of a scholarship to the first author (Proc. 2017/05031-2).

\section{References}

1- Camisasca DR, da Rós Goncalves L, Soares MR, Sandim V, Nogueira FC, Garcia $\mathrm{CH}$, et al. A proteomic approach to compare saliva from individuals with and without oral leukoplakia. J Proteomics. 2017; 151:43-52

2- Castagnola M, Cabras T, Iavarone F, Vincenzoni F, Vitali A, Pisano E, et al. Top-down platform for deciphering the human salivary proteome. J Matern Fetal Neonatal Med. 2012;25(Suppl 5):27-43.

3- Castagnola M, Scarano E, Passali GC, Messana I, Cabras T, Iavarone $F$, et al. Salivary biomarkers and proteomics: future diagnostic and clinical utilities. Acta Otorhinolaryngol Ital. 2017;37(2):94-101.

4- Catherman AD, Skinner OS, Kelleher NL. Top Down proteomics: facts and perspectives. Biochem Biophys Res Commun. 2014;445(4):68393.

5- Hannig M. Ultrastructural investigation of pellicle morphogenesis at two different intraoral sites during a $24-\mathrm{h}$ period. Clin Oral Investig. $1999 ; 3(2): 88-95$.

6- Jasim H, Olausson P, Hedenberg-Magnusson B, Ernberg M, Ghafour $B$. The proteomic profile of whole and glandular saliva in healthy painfree subjects. Sci Rep. 2016;6:39073.

7- Krief G, Deutsch O, Gariba S, Zaks B, Aframian DJ, Palmon A. Improved visualization of low abundance oral fluid proteins after triple depletion of alpha amylase, albumin and IgG. Oral Dis. 2011;17(1):4552.

8- Krief G, Deutsch O, Zaks B, Wong DT, Aframian DJ, Palmon A. Comparison of diverse affinity based high-abundance protein depletion strategies for improved bio-marker discovery in oral fluids. J Proteomics. 2012;75(13):4165-75.

9- Manconi B, Liori B, Cabras T, Iavarone F, Manni A, Messana I, et al. Top-down HPLC-ESI-MS proteomic analysis of saliva of edentulous subjects evidenced high levels of cystatin A, cystatin B and SPRR3. Arch Oral Biol. 2017;77:68-74.

10- Messana I, Cabras T, Iavarone F, Vincenzoni F, Urbani A, Castagnola M. Unraveling the different proteomic platforms. J Sep Sci. 2013;36(1):128-39.

11- Nesatyy VJ, Suter MJ. Analysis of environmental stress response on the proteome level. Mass Spectrom Rev. 2008;27(6):556-74. 
12- Peng Y, Chen X, Sato T, Rankin SA, Tsuji RF, Ge Y. Purification and high-resolution top-down mass spectrometric characterization of human salivary alpha-amylase. Anal Chem. 2012;84(7):3339-46. 13- Schweigel $H$, Wicht M, Schwendicke F. Salivary and pellicle proteome: a datamining analysis. Sci Rep. 2016;6:38882.

14- Sivadasan P, Gupta MK, Sathe GJ, Balakrishnan L, Palit P, Gowda $\mathrm{H}$, et al. Human salivary proteome - a resource of potential biomarkers for oral cancer. J Proteomics. 2015;127(Pt A):89-95.

15- Tipton JD, Tran JC, Catherman AD, Ahlf DR, Durbin KR, Kelleher NL. Analysis of intact protein isoforms by mass spectrometry. J Biol Chem. 2011;286(29):25451-8.

16- Ventura TM, Cassiano LP, Souza e Silva CM, Taira EA, Leite AL, Rios

$D$, et al. The proteomic profile of the acquired enamel pellicle according to its location in the dental arches. Arch Oral Biol. 2017;79:20-9.
17- Wang X, Kaczor-Urbanowicz KE, Wong DT. Salivary biomarkers in cancer detection. Med Oncol. 2017;34(1):7.

18- Winck FV, Prado Ribeiro AC, Ramos Domingues R, Ling LY, RiañoPachón DM, Rivera $C$, et al. Insights into immune responses in oral cancer through proteomic analysis of saliva and salivary extracellular vesicles. Sci Rep. 2015;5:16305.

19- Wu S, Brown JN, Tolić N, Meng D, Liu X, Zhang H, et al. Quantitative analysis of human salivary gland-derived intact proteome using topdown mass spectrometry. Proteomics. 2014;14(10):1211-22.

20- Xiao H, Wong DT. Proteomic analysis of microvesicles in human saliva by gel electrophoresis with liquid chromatography-mass spectrometry. Anal Chim Acta. 2012;723:61-7. 